\title{
Horner's Syndrome Secondary to Angiogram Negative, Subadventitial Carotid Artery Dissection
}

\author{
M. Assaf, P.J. Sweeney, G. Kosmorsky and T. Masaryk
}

\begin{abstract}
A 59-year-old man presented with the acute onset of paresthesias and pain in the left neck, face, and forehead. On subsequent investigation he was found to have a subadventitial type of carotid artery dissection, producing an ipsilateral Horner's syndrome with normal carotid angiography. MRI imaging of the neck structures, using fat saturation technique, showed the subadventitial dissection, sparing the vessel lumen. MRI offers a non-invasive method of diagnosis and follow-up for carotid artery dissection.
\end{abstract}

RÉSUMÉ: Syndrome de Horner secondaire a une dissection sous-adventitielle de la corotide, non visualisée à l'angiographie. Un homme de 59 ans an consulté pour des paresthesies et une douleur à début subit du côté gauche du cou, de la face et du front. L'investigation a montré une dissection de type sous-adventitielle de la carotide causant un syndrome de Homer ipsilatéral avec une carotide normale à l'angiographie. L'imagerie par MRI des structures du cou, par la technique de saturation des graisses, a montré une dissection sous-adventitielle épargnant la lumière de l'artère. Le MRI est une méthode non-invasive de diagnostic et de suivi de la dissection de la carotide.

Can. J. Neurol. Sci. 1993; 20:62-64

The extracranial carotid artery is the most frequently reported site of cervicocerebral vessel dissection, occurring predominantly in middle age with a slight male predominance.' An ipsilateral Horner's syndrome occurs in 40 to $50 \%$ of patients with carotid dissection, secondary to involvement of the carotid sympathetic sheath. ${ }^{2}$ This report describes an unusual variety of carotid dissection and indicates the usefulness of MRI in diagnosis.

\section{Case Report}

A previously healthy 59-year-old man reported the abrupt onset of aching in the left cheek and malar area. This was soon followed by paresthesias in the left anterolateral neck. Within 30 minutes of onset, an ipsilateral frontal orbital headache appeared with nonspecific dizziness. Over the next 24 hours he noted drooping of the left upper eyelid. There was no history of recent neck trauma or strenuous rotation of his head and neck.

Physical examination revealed blood pressure of 160/120. Complete neurological examination revealed only a left Horner's syndrome which, on pharmacological testing with hydroxyamphetamine (Paredrine), indicated a third order neuron (postganglionic) lesion.

Hematological, urine, and blood chemistries were normal. Chest $X$-ray and head CT were normal. Carotid ultrasound, four vessel IADSA (Figures IA \& 1B), conventional head MRI, and an MR angiogram were nondiagnostic for carotid artery dissection. Axial T1- weighted MR imaging of the cervical structures, however (Figure 2), showed increased signal along the outer wall of the left carotid artery with a normal luminal flow void. Repeat $\mathrm{Tl}$-weighted scan with RF flat saturation of the same area (Figure 3) showed increased signal along the external wall of the internal carotid artery highly suggestive of a subadventitial dissection.

\section{Discussion}

Carotid artery dissection, spontaneous or traumatic, may manifest as a transient ischemic attack, stroke or simply as pain in the ipsilateral neck, face, or head. Other manifestations include lower cranial nerve dysfunction or Horner's syndrome. ${ }^{3}$ Posterior circulation dissection are less common than anterior and affect mainly healthy young adults. They carry a higher mortality and morbidity. ${ }^{4}$

The etiology for either type may be traumatic or spontaneous. In some patients fibromuscular dysplasia or Marfan's syndrome is the etiology.

Pathologically, hemorrhage in the subadventitial layer of the carotid artery is less common than either subintimal and medial hemorrhage. In extracranial carotid dissection, a hematoma in the subadventitial layer often produces a pseudoaneurysm ${ }^{5}$ and less frequently communicates with the true lumen. In the much

From the Departments of Neurology (M.A., P.J.S., G.K.), Ophthalmology (G.K.), Radiology (T.M.), The Cleveland Clinic Foundation, Cleveland, U.S.A.

Received December 16, 1991. Accepted in final form August 12, 1992

Reprint requests to: Patrick J. Sweeney, MD, The Cleveland Clinic Foundation, One Clinic Center, 9500 Euclid Avenue, Cleveland, Ohio, U.S.A. 44195-5223 


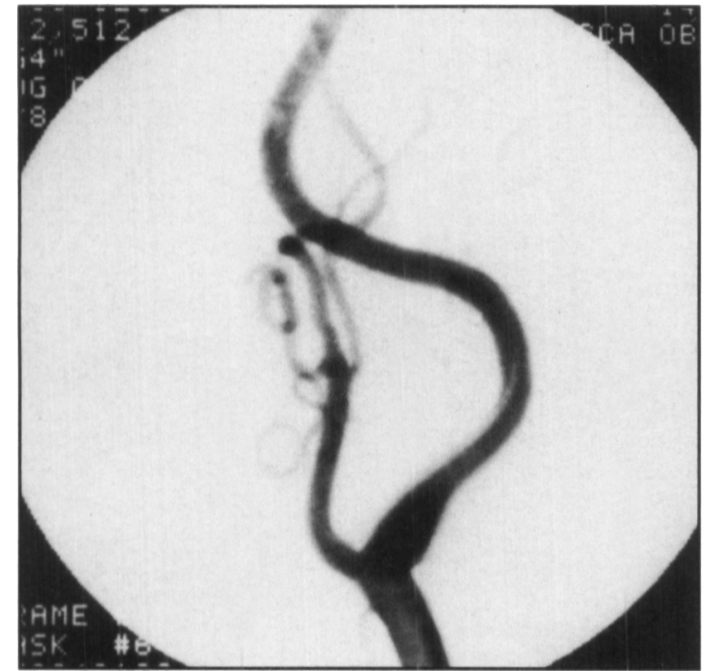

A

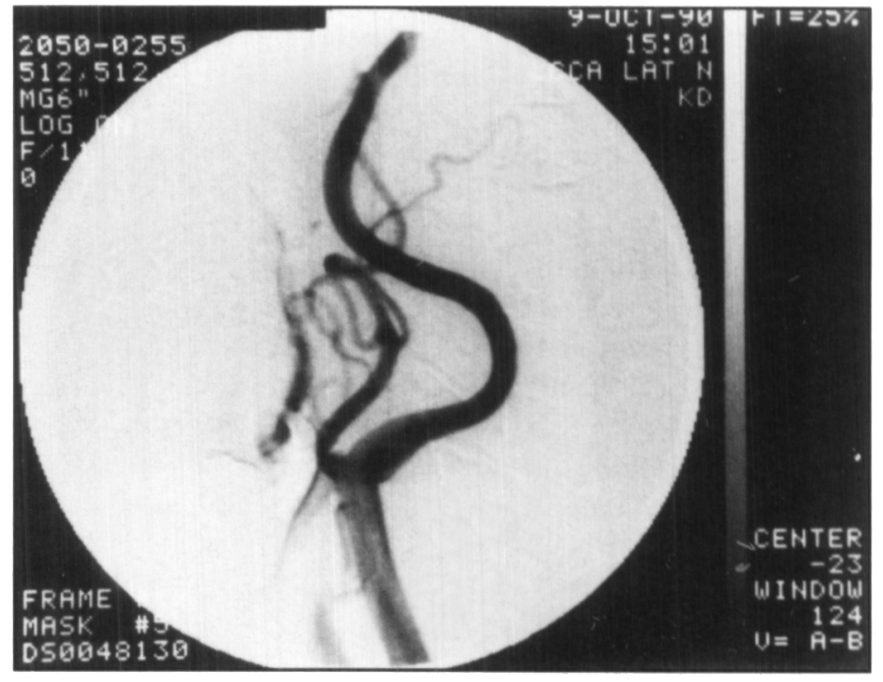

B

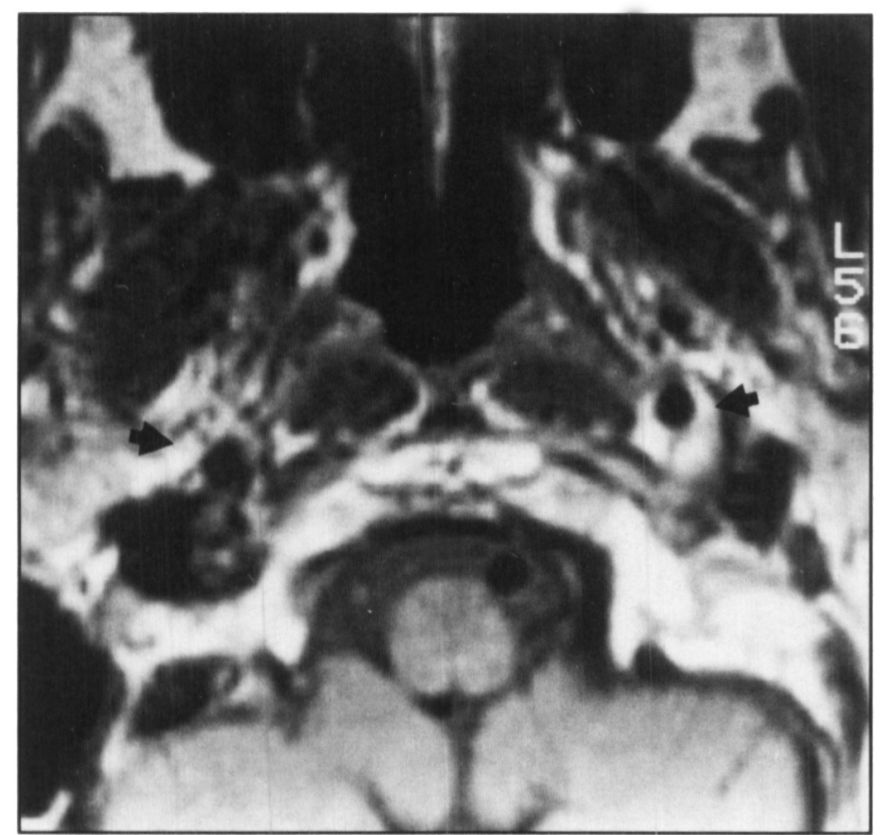

Figure 2 - Axial Tl-weighted spin-echo image through the distal cervical intimal carotid arteries. A saturation pulse was placed below the region of interest to eliminate flow artifact. Note the extensive fat about the vessels in the carotid space. Nevertheless, this bright signal appears excessive on the left.

more common subintimal variety, a hematoma occurs beneath the intima and compromises the lumen, producing marked narrowing which accounts for the characteristic angiographic findings.

Fisher et al. ${ }^{6}$ reviewed the arteriographic features of dissections of the cervical carotid artery. Tapered occlusion of the artery is the least specific arteriographic abnormality ${ }^{1,5,6}$ found in $20 \%$ of cases. ${ }^{\prime}$

The most frequent finding is marked irregular narrowing of the artery which results in the so-called "String Sign", a highly characteristic but nonspecific feature..$^{1.6 .7}$

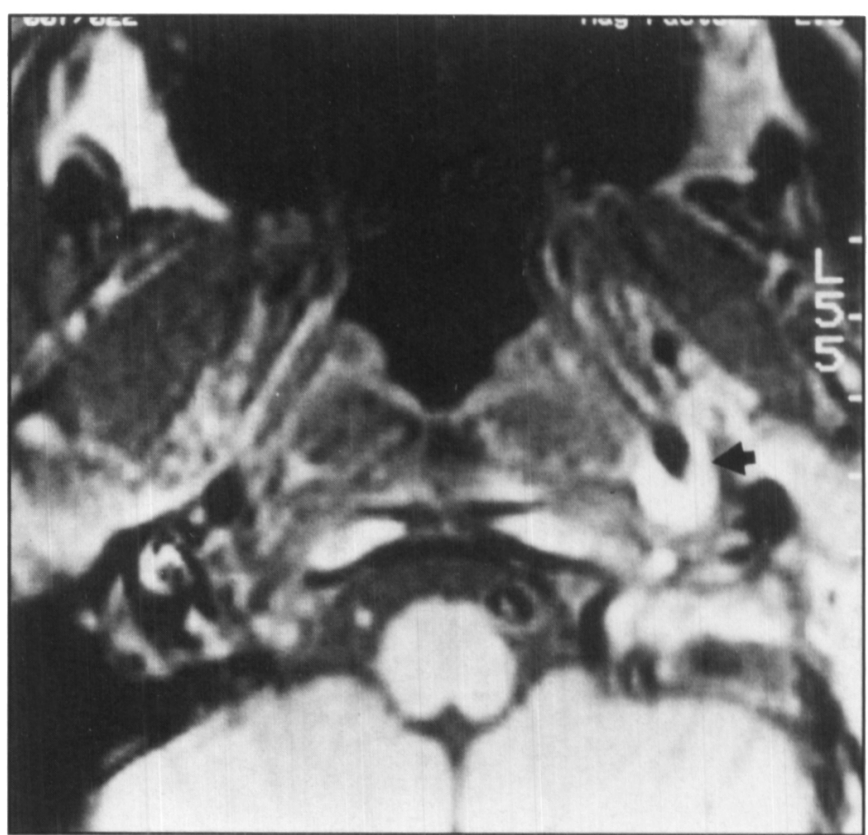

Figure 3 - Axial Tl-weighted spin-echo image with a frequency selective fat saturation pulse over the region of interest and a second saturation pulse below to eliminare flow artifact. This sequence is designed to suppress fat signal around the vessels. Note the persistent perivascular high signal on the left, indicative of paramagnetic effect of thrombus.

Because of the variability of the angiographic findings, the use of other modalities such as MRI and carotid duplex examinations have been reported to be useful as non-invasive techniques in the diagnosis of dissection. The process typically occurs just distal to the extracranial bifurcation - usually at or around the C-2 vertebral level. It may be beyond the range of carotid sonography. ${ }^{8}$

Masaryk et al., ${ }^{9}$ by using the 3D Time-of-Flight angiography, showed the lesion in a fashion comparable to the patient's angiogram in two cases, one with severe atherosclerosis and the 
other with carotid dissection. Bogousslavsky et al. ${ }^{10}$ suggested that sequential doppler examination should be done systemically in patients with suspected early carotid dissection.

In our case, the use of axial MR with the addition of RF fat saturation techniques, allowed diagnosis of this unusual subadventitial variety of carotid dissection. Fat saturation is advantageous because of its ability to increase the conspicuousness of perivascular hemorrhage by suppressing fat signal in the carotid and parapharyngeal spaces."

The value of fat saturation MRI in diagnosing carotid dissection has been discussed by Goldberg et al., ${ }^{2}$ MR has the ability to show the vascular lumen and arterial wall non-invasively without use of contrast material. The technique of fat saturation MRI allowed us to non-invasively image the carotid wall and demonstrate the presence of a subadventitial type, carotid artery dissection.

\section{REFERENCES}

1. Hart RG, Easton D. Dissection of cervical and cerebral arteries. Neurol Clin 1983; 5: 155-182.

2. Mokri B, Sundt TM, Houser W. Spontaneous internal carotid dissection, hemicrania, and Horner's syndrome. Arch Neurol 1979; 36: $677-680$
3. Schievink WL, Limburg M. Dissection of cervical anteries as a cause of cerebral ischemic or cranial nerve dysfunction. Ned Tijdschr Geneeskd 1990; 134: 1843-1848.

4. Beger MS, Wilson CB. Intracranial dissection aneurysm of the post circulation. Report of six cases and review of the literature. $J$ Neurosurg 1984; 61: 882-894.

5. Luken MG, Ascherl GF, Correll JW, et al. Spontaneous dissection aneurysm of the extracranial internal carotid artery. Clin Neurosurg 1979; 26: 353-375.

6. Fisher CM, Ojemann RG, Roberson GH. Spontaneous dissection of cervicocerebral arteries. Can J Neurol Sci 1987; 5: 9-19.

7. Mehigan JT, Olcott C. The carotid String Sign - differential diagnosis. Am J Neurosurg 1980; 140: 137-143.

8. Pothrock JF, Lim V, Press G, et al. Serial magnetic resonance and carotid duplex examination in the management of carotid dissection. Neurology 1989; 39: 686-692.

9. Masaryk T, Ross J, Modic M. Carotid bifurcation: MR imaging. Radiology 1988; 166: 461-466.

10. Bogousslavsky J, Despland PA, Regli F. Spontaneous carotid dissection with acute stroke. Arch Neurol 1987; 44: 137-140.

11. Rosen BR, Carter EA, Pykett IL, et al. Proton chemical shift imaging: an evaluation of its clinical potential using an in vivo fatty liver model. Radiology 1985; 154: 469-472.

12. Goldberg HI, Grossman RI, Gomori JM, et al. Cervical internal carotid artery dissection hemorrhage: diagnosis using MR. Radiology 1986; 158: 157-161. 